\title{
A COMPARATIVE STUDY OF DYSLIPIDAEMIA IN SUBCLINICAL VERSUS OVERT HYPOTHYROIDISM
}

\author{
Anjali Jayakumar', Sharath Kumar D Shah'2, Suma K. $R^{3}$
}

1Junior Resident, Department of General Medicine, Sri Siddhartha Medical College, Tumkur, Karnataka.

2Professor and HOD, Department of General Medicine, Sri Siddhartha Medical College, Tumkur, Karnataka. 3Professor, Department of General Medicine, Sri Siddhartha Medical College, Tumkur, Karnataka.

\section{BACKGROUND}

ABSTRACT

Hypothyroidism is a metabolic disorder with a cluster of clinical signs and symptoms, especially in middle-aged women. Spectrum of cardiovascular manifestation includes hypertension and dyslipidaemia, which are major causes of atherosclerosis and coronary artery disease. Altered lipid profile is a major expression in overt hypothyroidism according to many previous studies. We have established the relationship in subclinical hypothyroidism.

Aim and Objective-

1. The aim of this study is to improve the ability to diagnose unsuspected dyslipidaemia, especially in subclinical hypothyroidism to reduce further morbidity.

2. The objective of this study is to assess and compare varying degree of dyslipidaemia in subclinical and overt hypothyroidism patients.

\section{MATERIALS AND METHODS}

This is a descriptive study. The present study was carried out in the Department of General Medicine at Sri Siddhartha Medical College, Tumkur, Karnataka, with 100 patients (50 subclinical hypothyroidism and 50 overt hypothyroidism patients). Thyroid Profile was done with CLIA (chemiluminescence immunoassay) system. Lipid Profile was done with semi-automated analyser.

\section{RESULTS}

In the present study, the mean total cholesterol values were $195.2 \pm 42.27$ and $180.76 \pm 41.32$; Triglycerides values were $155.44 \pm$ $42.69,152.2 \pm 32.82$; HDL values were $45.46 \pm 5.02$, $46.64 \pm 5.32$; and LDL values were $124.43 \pm 42.45$, $119.75 \pm 39.99$ respectively in the subclinical hypothyroidism and overt hypothyroidism.

\section{CONCLUSION}

In overt hypothyroid group, TSH showed statistically significant positive correlation with total cholesterol ( $\mathrm{r}=0.434, \mathrm{p}<0.0164)$, Triglyceride $(\mathrm{r}=0.339, \mathrm{p}<0.05)$ and LDL cholesterol $(\mathrm{r}=0.409, \mathrm{p}<0.05)$. TSH had negative correlation with HDL cholesterol $(\mathrm{r}=$ $-0.394, p<0.05)$. In Subclinical hypothyroid group, TSH showed statistically significant correlation with total cholesterol ( $r=0.387$, $\mathrm{p}<0.05)$, LDL-C $(\mathrm{r}=0.404, \mathrm{p}<0.05)$. The correlation between TSH was statistically not significant for Triglyceride, VLDL and HDLC. No direct correlation was found between TSH levels and degree of dyslipidaemia. The study has demonstrated and has further proved that hypothyroidism also causes significant dyslipidaemia in subclinical hypothyroidism.

\section{KEYWORDS}

Subclinical Hypothyroidism, Overt Hypothyroidism, TSH, Dyslipidaemia, Lipid Profile, Atherogenic Pattern, Cardiovascular Morbidity.

HOW TO CITE THIS ARTICLE: Jayakumar A, Shah SKD, Suma KR. A comparative study of dyslipidaemia in subclinical versus overt hypothyroidism. J. Evolution Med. Dent. Sci. 2018;7(03):279-283, DOI: 10.14260/jemds/2018/62

\section{BACKGROUND}

Hypothyroidism is a common metabolic disorder in the general population. World Health Organisation (WHO) estimates that about 2 billion people are iodine-deficient based on urinary excretion data. ${ }^{1}$ It is estimated that about 200 million people are at the risk of Iodine Deficiency Disease in our country. ${ }^{2}$ A cross-sectional, multi-centre, epidemiological study conducted in eight major cities (Bangalore, Chennai, Delhi, Goa, Mumbai, Hyderabad, Ahmedabad and Kolkata) of India concluded that the prevalence of hypothyroidism was high affecting 1 in 10 adults in the

'Financial or Other Competing Interest': None.

Submission 31-10-2017, Peer Review 30-12-2017,

Acceptance 06-01-2018, Published 13-01-2018.

Corresponding Author:

Dr. Anjali Jayakumar,

Rohan Ashima, Villa No. 4,

Ryan School Road, Brookfield, Bangalore-37.

E-mail: dranjali2806@gmail.com

DOI: 10.14260/jemds/2018/62 study population, is higher in females. ${ }^{3}$ In general overt and subclinical hypothyroidism is associated with hypercholesterolaemia, mainly due to elevation of low density lipoprotein (LDL) cholesterol levels, whereas high density lipoprotein (HDL) cholesterol concentration is usually normal or even elevated.4-6 Thyroid hormone has a major effect on the lipoprotein metabolism, which stimulates the hepatic de novo cholesterol synthesis by inducing the 3hydroxy-methyl-glutaryl-coenzyme A (HMG-CoA) reductase that catalyses the conversion of HMG-CoA to mevalonate, the first step in the biosynthesis of cholesterol. ${ }^{7}$ It is proved that thyroid substitution is beneficial for patients with overt hypothyroidism, but whether or not to treat subclinical hypothyroidism remains controversial. Subclinical hypothyroidism (SH) refers to biochemical evidence of thyroid hormone deficiency in patients who have few or no apparent clinical features of hypothyroidism. There are no universally accepted recommendations for the management. When TSH levels are below $10 \mathrm{mIU} / \mathrm{L}$, treatment should be considered when patients have suggestive symptoms of hypothyroidism, positive TPO antibodies or any evidence of 
heart disease. It is important to confirm that any elevation of TSH is sustained over a 3-month period before treatment is given.

Hypothyroidism is defined as failure of the thyroid gland to produce sufficient thyroid hormone to meet the metabolic demands of the body. Untreated hypothyroidism can contribute to hypertension, dyslipidaemia, infertility, cognitive impairment and neuromuscular dysfunction. The prevalence increases with age and is higher in females than in males. Efstathiadou et $\mathrm{al}^{8}$ evaluated the serum lipid parameters of 66 patients with SH and 75 age- and sexmatched euthyroid controls and found SH had significantly higher levels of total cholesterol, LDL cholesterol, apolipoprotein B and Lp (a), whereas levels of triglycerides, HDL cholesterol and apolipoprotein did not differ significantly compared to euthyroid controls.

A recent Indian study by Marwaha $\mathrm{RK}$ et $\mathrm{al}^{9}$ on dyslipidaemia in subclinical hypothyroidism in an Indian population shows that no atherogenic lipid abnormalities were found in adult subjects with subclinical hypothyroidism with TSH < $10.0 \mathrm{mIU} / \mathrm{L}$; however, significant correlation has been found when the TSH is between $10.1 \mathrm{mIU} / \mathrm{L}$ and 20 $\mathrm{mIU} / \mathrm{L}$ in subjects with subclinical hypothyroidism.

\section{Aim}

To improve the ability to diagnose unsuspected dyslipidaemia, especially in subclinical hypothyroidism to reduce further morbidity. The objective is to assess and compare varying degree of dyslipidaemia in subclinical and overt hypothyroidism patients.

\section{MATERIALS AND METHODS}

This is a descriptive study. The present study was carried out in the Department of General Medicine, Sri Siddhartha Medical College, Tumkur, Karnataka, with 100 patients (50 Subclinical hypothyroidism and 50 Overt hypothyroidism patients). Sample size was taken conveniently. The period of the study extended to about two years. All the patients' venous blood sample was withdrawn for investigation of Total triiodothyronine (T3), Total thyroxine (T4) and thyroid stimulating hormone (TSH) and in Lipid Profile- Total cholesterol, LDL, Triglyceride, Cholesterol, HDL and VLDL was done. After explaining the nature, procedure, purpose and other relevant details of the study, verbal informed consent were taken from all the subjects.

Thyroid Profile was done with CLIA (chemiluminescence immunoassay) system. Lipid Profile was done with semiautomated analyser.

\section{The following guidelines for lab values were followed- LDL Cholesterol}

Optimal: Less than $100 \mathrm{mg} / \mathrm{dL}$ (2.59 mmol/L); for those with known disease (ASCVD or diabetes), less than $70 \mathrm{mg} / \mathrm{dL}(1.81$ $\mathrm{mmol} / \mathrm{L}$ ) is optimal.

Near/above optimal: 100-129 mg/dL (2.59-3.34 mmol/L) Borderline high: $130-159 \mathrm{mg} / \mathrm{dL}$ (3.37-4.12 mmol/L)

High: $160-189 \mathrm{mg} / \mathrm{dL}$ (4.15-4.90 mmol/L)

Very High: Greater than $190 \mathrm{mg} / \mathrm{dL}$ (4.90 mmol/L)

\section{Total Cholesterol}

Desirable: Less than $200 \mathrm{mg} / \mathrm{dL}$ (5.18 mmol/L)

Borderline High: $200-239 \mathrm{mg} / \mathrm{dL}$ (5.18 to $6.18 \mathrm{mmol} / \mathrm{L}$ )

High: $240 \mathrm{mg} / \mathrm{dL}$ (6.22 mmol/L) or higher.

\section{HDL Cholesterol}

Low level, increased risk: Less than $40 \mathrm{mg} / \mathrm{dL}(1.0 \mathrm{mmol} / \mathrm{L})$ for men and less than $50 \mathrm{mg} / \mathrm{dL}(1.3 \mathrm{mmol} / \mathrm{L})$ for women. Average level, average risk: $40-50 \mathrm{mg} / \mathrm{dL}$ (1.0-1.3 mmol/L) for men and between $50-59 \mathrm{mg} / \mathrm{dL}$ (1.3-1.5 mmol/L) for women.

High level, less than average risk: $60 \mathrm{mg} / \mathrm{dL}(1.55 \mathrm{mmol} / \mathrm{L})$ or higher for both men and women.

\section{Fasting Triglycerides}

Desirable: Less than $150 \mathrm{mg} / \mathrm{dL}(1.70 \mathrm{mmol} / \mathrm{L})$

Borderline high: $150-199 \mathrm{mg} / \mathrm{dL}(1.7-2.2 \mathrm{mmol} / \mathrm{L})$

High: $200-499 \mathrm{mg} / \mathrm{dL}$ (2.3-5.6 mmol/L)

Very High: Greater than $500 \mathrm{mg} / \mathrm{dL}$ (5.6 mmol/L)

T4 - 70-151 nmol/L

$\mathrm{T} 3-1.2-2.1 \mathrm{nmol} / \mathrm{L}$

TSH - 0.34-4.25 mIU/L

\section{Inclusion Criteria}

1. Newly detected hypothyroidism.

2. Old uncontrolled hypothyroidism.

\section{Exclusion Criteria}

1. Subjects with known dyslipidaemia.

2. Patients taking lipid lowering medicine.

3. Patients with congenital heart disease, rheumatic heart disease, diabetes mellitus, smoking, alcohol, COPD and severe anaemia.

Ethical approval was granted by SSAHE University, Tumkur, Karnataka.

\section{Methodology Data Analysis}

The analysis was done using standard Statistical Package for Social Sciences (SPSS) software version 24. The collected data were entered into an excel sheet. The data were expressed in means, medians and proportions and presented in the form of tables and graphs wherever necessary. Simple descriptive measures like mean, standard deviation and variables of lipid profile in hypothyroidism analysed using Chi-square test, student's ' $t$ ' test. The continuous variables were expressed in means or medians and categorical variables were expressed in proportions. Correlation between variables were done using Pearson correlation test. The comparison of means of various parameters with normal subjects, subclinical and overt hypothyroid patients was done using independent ttest. The association of categorical variables were analysed using Chi-square test. P-value of $<0.05$ was taken as statistically significant.

\section{RESULTS}

The study was conducted in Sri Siddhartha Medical College Hospital, Tumkur, Karnataka over a period of two years, a total of 100 patients were enrolled in this study. 


\begin{tabular}{|c|c|c|c|c|c|c|c|}
\hline & $<20$ years & $\mathbf{2 0 - 3 0}$ years & $\mathbf{3 1 - 4 0}$ years & $\mathbf{4 1 - 5 0}$ years & $\mathbf{5 1 - 6 0}$ years & >60 years & Total \\
\hline Overt & $\begin{array}{c}3 \\
(6 \%)\end{array}$ & $15(30 \%)$ & $12(24 \%)$ & $11(22 \%)$ & $\begin{array}{c}6 \\
(12 \%)\end{array}$ & $\begin{array}{c}3 \\
(6 \%)\end{array}$ & 50 \\
\hline Subclinical & $\begin{array}{c}2 \\
(4 \%)\end{array}$ & $16(32 \%)$ & $13(26 \%)$ & $11(22 \%)$ & $\begin{array}{c}7 \\
(14 \%)\end{array}$ & 50 \\
$(2 \%)$
\end{tabular}

Table 1. Distribution of Overt and Subclinical Hypothyroidism by Age

\begin{tabular}{|c|c|c|c|}
\hline \multicolumn{2}{|c|}{ Overt } & Male & Female \\
\hline Male & Female & 0 & $50(100 \%)$ \\
\hline $10(20.0 \%)$ & $40(80 \%)$ & Table 2. Distribution of Overt and Subclinical Hypothyroidism by Gender \\
\hline
\end{tabular}

\begin{tabular}{|c|c|c|c|c|c|c|c|c|}
\hline Overt & Gender & $<20$ years & $20-30$ years & $31-40$ years & 41-50 years & $51-60$ years & $>60$ years & Total \\
\hline Male & Count & $0(0 \%)$ & $3(30 \%)$ & $3(30 \%)$ & $2(20 \%)$ & $2(20 \%)$ & $0(0 \%)$ & $10(100 \%)$ \\
\hline Female & Count & $3(8 \%)$ & $12(30 \%)$ & $9(23 \%)$ & $9(23 \%)$ & $4(10 \%)$ & $3(8 \%)$ & $40(100 \%)$ \\
\hline \multicolumn{9}{|c|}{ Chi Square $=2.377, P=.795$} \\
\hline Subclinical & Female & $2(4 \%)$ & $16(32 \%)$ & $13(26 \%)$ & $11(22 \%)$ & $7(14 \%)$ & $1(2 \%)$ & $50(100 \%)$ \\
\hline
\end{tabular}

\begin{tabular}{|c|c|c|c|c|c|c|}
\hline & N & Minimum & Maximum & Mean & Std. Error & Std. Deviation \\
\hline Overt & 50 & 18 & 70 & 38.56 & 1.889 & 13.360 \\
\hline Subclinical & 50 & 17 & 61 & 37.72 & 1.703 & 12.044 \\
\hline \multicolumn{7}{|c|}{ Table 4. Mean of Age in Different Groups } \\
\hline
\end{tabular}

\begin{tabular}{|c|c|c|c|c|c|c|c|c|}
\hline & \multirow[b]{2}{*}{ Overt } & \multirow[b]{2}{*}{ Subclinical } & \multicolumn{2}{|c|}{$\begin{array}{c}\text { Comparison } \\
\text { between Overt } \\
\text { and Subclinical }\end{array}$} & \multicolumn{2}{|c|}{$\begin{array}{c}\text { Comparison } \\
\text { between Normal } \\
\text { and Overt }\end{array}$} & \multicolumn{2}{|c|}{$\begin{array}{c}\text { Comparison } \\
\text { between Normal } \\
\text { and Subclinical }\end{array}$} \\
\hline & & & $\mathbf{t}$ & $\mathbf{P}$ & $\mathbf{t}$ & $\mathbf{P}$ & $\mathbf{t}$ & $\mathbf{P}$ \\
\hline Total cholesterol & $195.2 \pm 42.27$ & $180.76 \pm 41.32$ & 1.728 & .087 & -31.79 & 0.000 & -30.05 & 0.000 \\
\hline Triglycerides & $155.44 \pm 42.69$ & $152.2 \pm 32.82$ & .425 & .672 & -25.47 & 0.000 & -32.43 & 0.000 \\
\hline LDL & $124.43 \pm 42.45$ & $119.75 \pm 39.99$ & .567 & .572 & -20.30 & 0.000 & -20.72 & 0.000 \\
\hline
\end{tabular}

\begin{tabular}{|c|c|c|c|c|c|c|c|c|c|c|c|}
\hline & & & \multirow{3}{*}{$\begin{array}{c}\text { Subclinical } \\
\text { Female }\end{array}$} & \multicolumn{2}{|c|}{$\begin{array}{c}\text { Comparison } \\
\text { between Overt } \\
\text { and Subclinical }\end{array}$} & \multicolumn{4}{|c|}{$\begin{array}{c}\text { Comparison between Normal and } \\
\text { Overt }\end{array}$} & \multicolumn{2}{|c|}{\begin{tabular}{|c|} 
Comparison \\
between Normal \\
and Subclinical
\end{tabular}} \\
\hline \multirow{3}{*}{ HDL } & \multicolumn{2}{|c|}{ Overt } & & $\mathbf{t}$ & $\mathbf{P}$ & \multicolumn{2}{|c|}{$t$} & \multicolumn{2}{|c|}{$\mathbf{P}$} & $\mathbf{t}$ & $\mathbf{P}$ \\
\hline & Male & Female & & $\mathbf{F}$ & $\mathbf{F}$ & $\mathbf{M}$ & $\mathbf{F}$ & $\mathbf{M}$ & $\mathbf{F}$ & $\mathbf{F}$ & $\mathbf{F}$ \\
\hline & $43.87 \pm 6.0$ & $45.85 \pm 4.75$ & $46.64 \pm 5.32$ & -.729 & .468 & 50.16 & 65.96 & 0.000 & 0.000 & -59.99 & 0.000 \\
\hline
\end{tabular}

\begin{tabular}{|c|c|c|c|c|}
\hline \multirow{2}{*}{ TSH Level (mIU/L) } & \multicolumn{2}{|c|}{ Overt } & Subclinical \\
\cline { 2 - 5 } & No. of Cases & $\mathbf{\%}$ & 4 & No. of Cases \\
\hline$<5.5$ & 0 & 0 & 45 & 8.0 \\
\hline $5.6-10.9$ & 0 & 0 & 0 & 90.0 \\
\hline $11-30$ & 3 & 30.0 & 0 & 0.0 \\
\hline $31-60$ & 15 & 64.0 & 1 & 0.0 \\
\hline 61 and above & 32 & Table 6. Distribution of Cases according to TSH Level Range \\
\hline
\end{tabular}

\begin{tabular}{|c|c|c|c|c|}
\hline & \multicolumn{2}{|c|}{ Overt } & \multicolumn{2}{c|}{ Subclinical } \\
\hline & No. of Cases & No. of Cases & \% \\
\hline$<5.5$ & 38 & 76.0 & 0 & 00.0 \\
\hline $5.6-10.9$ & 2 & 4.0 & 1 & 2.0 \\
\hline $11-30$ & 2 & 4.0 & 1 & 2.0 \\
\hline $31-60$ & 1 & 2.0 & 8 & 16.0 \\
\hline 61 and above & 7 & 14.0 & $\mathbf{5 0}$ & $\mathbf{1 0 0 . 0}$ \\
\hline Total & $\mathbf{5 0}$ & $\mathbf{1 0 0 . 0}$ & \\
\hline
\end{tabular}




\begin{tabular}{|c|c|c|c|c|}
\hline & \multicolumn{2}{|c|}{ Overt } & \multicolumn{2}{c|}{ Subclinical } \\
\hline & No. of Cases & $\mathbf{\%}$ & No. of Cases & \% \\
\hline$<5.5$ & 45 & 90.0 & 30 & 34.0 \\
\hline $5.6-10.9$ & 4 & 8.0 & 17 & 4.0 \\
\hline $11-30$ & 1 & 2.0 & 2 & 2.0 \\
\hline 61 and above & 0 & 0.0 & 1 & \\
\hline
\end{tabular}

\begin{tabular}{|c|c|c|c|c|c|c|c|}
\hline & & $<\mathbf{2 0}$ years & $\mathbf{2 0 - 3 0}$ years & $\mathbf{3 1 - 4 0}$ years & $\mathbf{4 1 - 5 0}$ years & $\mathbf{5 1 - 6 0}$ years & $>\mathbf{6 0}$ years \\
\hline \multirow{2}{*}{ Total cholesterol } & Overt & $217.67 \pm 60.12$ & $185.33 \pm 38.03$ & $200.67 \pm 38.95$ & $196.91 \pm 50.28$ & $205.33 \pm 41.45$ & $173.67 \pm 45.5$ \\
\cline { 2 - 8 } & Subclinical & $203.5 \pm 86.97$ & $155.31 \pm 25.06$ & $195.46 \pm 49.17$ & $188.45 \pm 43.97$ & $189.43 \pm 19.55$ & $206 \pm 0$ \\
\hline \multirow{2}{*}{ Triglycerides } & Overt & $141.33 \pm 4.16$ & $143.33 \pm 21.39$ & $151.83 \pm 59.8$ & $163.09 \pm 46.54$ & $187 \pm 47.38$ & $153.33 \pm 23.09$ \\
\cline { 2 - 8 } & Subclinical & $140.5 \pm 34.65$ & $143.01 \pm 42.75$ & $161.92 \pm 31.85$ & $153.09 \pm 22.72$ & $152.29 \pm 21.7$ & $186 \pm 0$ \\
\hline \multirow{2}{*}{ HDL } & Overt & $50 \pm 3.46$ & $45.82 \pm 5.64$ & $46.01 \pm 3.33$ & $43.29 \pm 5.17$ & $44.2 \pm 5$ & $47.33 \pm 7.57$ \\
\cline { 2 - 8 } & Subclinical & $49 \pm 7.07$ & $46.82 \pm 5.74$ & $44.17 \pm 4.69$ & $46.64 \pm 6.02$ & $49.94 \pm 2.83$ & $48 \pm 0$ \\
\hline \multirow{2}{*}{ LDL } & Overt & $113 \pm 16.46$ & $133.81 \pm 58.27$ & $116.37 \pm 14.85$ & $126.73 \pm 54.49$ & $120.33 \pm 29.23$ & $121 \pm 23.81$ \\
\cline { 2 - 8 } & Subclinical & $149 \pm 80.61$ & $99.56 \pm 17.9$ & $139.38 \pm 53.61$ & $125.51 \pm 38.92$ & $110.57 \pm 22.82$ & $130 \pm 0$ \\
\hline \multicolumn{7}{|c|}{ Table 9. Parameters Observed in Overt and Subclinical Hypothyroidism in Different Age Group } \\
\end{tabular}

\begin{tabular}{|c|c|c|c|c|}
\hline & \multicolumn{2}{c|}{ Overt } & \multicolumn{2}{c|}{ Subclinical } \\
\hline & Correlation coefficient & P value & Correlation coefficient & P value \\
\hline HDL vs. TSH & -0.084 & 0.561 & -0.092 & 0.525 \\
\hline Total cholesterol vs. TSH & 0.144 & 0.317 & 0.01 & 0.943 \\
\hline Triglycerides vs. TSH & 0.196 & 0.173 & 0.072 & 0.622 \\
\hline LDL vs. TSH & 0.124 & 0.391 & -0.007 & 0.96 \\
\hline \multicolumn{2}{c}{} \\
\hline
\end{tabular}

None of the values are significant.

\section{DISCUSSION}

At least one in every 10 persons in India is suffering from hypothyroidism ${ }^{3}$; hence, the predisposition towards morbidity, especially cardiovascular is high, out of which a number of cases go undiagnosed. It is estimated that 2\% - 5\% of SCH has a propensity to progress to overt hypothyroidism in 2 - 3 years. Our study included 100 cases of subclinical and overt hypothyroidism, who underwent lipid profile estimation. 50 cases belonged to subclinical and 50 cases belonged to overt hypothyroidism. Out of 50 subclinical cases, all were females (100\%). Similarly, out of 159 cases of overt hypothyroidism, majority $(80 \%)$ were females. This shows female preponderance of this clinical condition. Mean age of subclinical and overt hypothyroidism cases were 37.72 and 38.56 respectively. This range of presentation implies a preponderance to early presentation in females. Mean total cholesterol in between SCH and overt hypothyroidism patients was found to be non-significant. Sharma et al 10 showed a statistically significant positive correlation with total cholesterol $(\mathrm{r}=0.434, \mathrm{p}<0.0164)$. The Rotterdam study reported that total cholesterol was not elevated in $\mathrm{SCH} .{ }^{9} \mathrm{We}$ found statistically no significant difference in total TG levels between subclinical and overt hypothyroidism patients. Sharma et $\mathrm{al}^{10}$ concluded that the correlation between TSH was statistically not significant for Triglyceride. This result was similar to our study result. A recent study in SCH showed that transfer of triglycerides to HDL and phospholipids was lower than that in controls, while transfer of free and esterified cholesterol to HDL, HDL particle size and paraoxonase 1 activity did not exhibit any difference. ${ }^{10}$

In our study, the mean LDL levels between SCH and overt hypothyroidism patients were found to be statistically nonsignificant. In SCH, thyroid hormone deficiency leads to a decreased number of LDL receptors on the liver cell surface resulting in decreased uptake and degradation of LDL-C.

The key findings to our study was the positive correlation of Total cholesterol, Triglycerides, HDL and LDL in SCH patients when compared with normal range values. This is an indication that SCH has an atherogenic serum lipid profile pattern.

Asranna A et al11 reported a positive correlation between total cholesterol and mean LDL levels in SH compared to controls, but there was no statistically significant difference in the mean HDL, VLDL and triglyceride levels. Dr. Shivaleela M Biradar, 12 in a study of 60 subjects found a significant reduction in TC and LDL-C levels following levothyroxine therapy in SCH. The Colorado study, which screened 25,862 subjects found that mean TC and LDL-C progressively increased with increasing serum TSH levels. In the NHANES III, mean cholesterol levels were higher in people with subclinical hypothyroidism than in euthyroid controls. There were no differences in LDL-C or HDL-C levels. ${ }^{13}$ In the Rotterdam Study, TC was lower in women with subclinical hypothyroidism than in euthyroid women. ${ }^{14}$ Milionis et al ${ }^{15}$ 2005 and Toruner et $\mathrm{al}^{16}$ 2008, have delineated an increased triglyceride and decreased HDL levels in SCH.

\section{CONCLUSION}

Hypothyroidism is a female predominant metabolic disorder. No direct correlation was found between TSH levels and degree of dyslipidaemia. There was no significant difference seen in lipid parameters of subclinical and overt hypothyroidism subgroups. Importantly, the SCH patients' lipid profile was notable for an atherogenic pattern, which suggests a need to detect such cases where they are more prone for cardiovascular morbidity. 


\section{REFERENCES}

[1] Fauci AS, Kasper DL, Longo DL, et al. Harrison's principles of internal medicine. Chapter: Disorders of thyroid gland. 19th edn. McGraw Hill 2008:2292-3.

[2] Shah SN, Joshi SR. Think thyroid: special issue on Indian thyroid guidelines. Journal of Associations of Physicians of India 2011;59:6.

[3] Unnikrishnan AG, Kalra S, Sahay RK, et al. Prevalence of hypothyroidism in adults: an epidemiological study in eight cities of India. Indian J Endocrinol Metab 2013;17(4):647-52.

[4] Canaris GJ, Manowitz NR, Mayor G, et al. The colorado thyroid disease prevalence study. Arch Intern Med 2000;160(4):526-34.

[5] O'Brien T, Dinneen SF, O'Brien PC, et al. Hyperlipidemia in patients with primary and secondary hypothyroidism. Mayo Clin Proc 1993;68(9):860-6.

[6] Muls E, Rosseneu M, Blaton V, et al. Serum lipids and apolipoproteins A-I, A-II and B in primary hypothyroidism before and during treatment. Eur J Clin Invest 1984;14(1):12-5.

[7] Khanna VN. Comparison of dyslipidemia between overt and subclinical hypothyroidism. International Journal of Scientific Research 2016;5(8).

[8] Efstathiadou Z, Bitsis S, Milionis HJ, et al. Lipid profile in subclinical hypothyroidism: is L-thyroxine substitution beneficial? Eur J Endocrinol 2001;145(6):705-10.
[9] Marwaha RK, Tandon N, Garg MK, et al. Dyslipidemia in subclinical hypothyroidism in an Indian population. Clin Biochem 2011;44(14-15):1214-7.

[10] Sharma P, Patgiri D, Goyal S, et al. Hypothyroidism causing dyslipidemia in both subclinical \& overt hypothyroidism. Indian J Basic Appl Med Res 2013;7(2):779-88.

[11] Asranna A, Taneja RS, Kulshreshta B, et al. Dyslipidemia in subclinical hypothyroidism and the effect of thyroxine on lipid profile. Indian J Endocrinol Metab 2012;16(Suppl 2):S347-9.

[12] Biradar SM, Patil SR. Study of lipid profile in subclinical hypothyroidism. Int J Pharm Bio Sci 2015;6(3):(B)1- 6 .

[13] Hollowell JG, Staehling NW, Flanders WD, et al. Serum TSH, T(4), and thyroid antibodies in the United States population (1988 to 1994): national health and nutrition examination survey (NHANES III). J Clin Endocrinol Metab 2002;87(2):489-99.

[14] Hofman A, Brusselle GG, Murad SD, et al. The rotterdam study: 2016 objectives and design update. Eur J Epidemiol 2015;30(8):661-708.

[15] Milionis HJ, Tambaki AP, Kanioglou CN, et al. Thyroid substitution therapy induces high-density lipoproteinassociated platelet-activating factor-acetylhydrolase in patients with subclinical hypothyroidism: a potential antiatherogenic effect. Thyroid 2005;15(5):455-60.

[16] Toruner F, Altinova AE, Karakoc A, et al. Risk factors for cardiovascular disease in patients with subclinical hypothyroidism. Adv Ther 2008;25(5):430-7. 